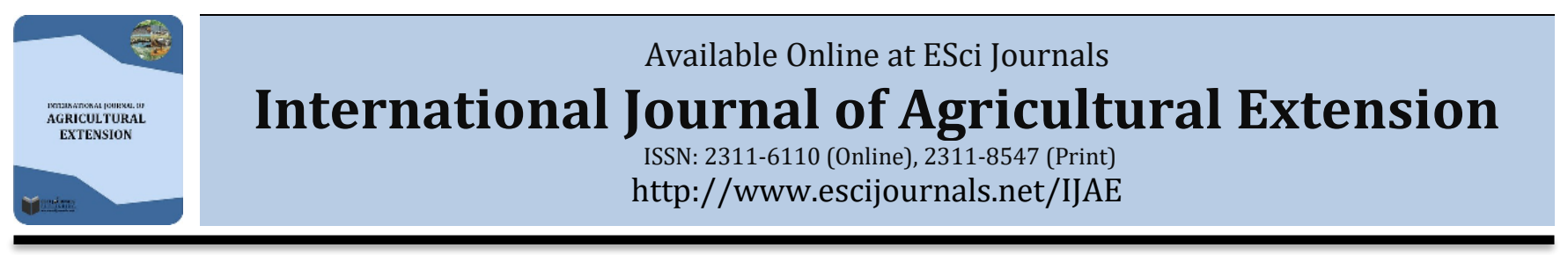

\title{
FACTORS IMPEDING CITRUS SUPPLY CHAIN IN CENTRAL PUNJAB, PAKISTAN
}

\author{
Muhammad Usman, Ijaz Ashraf, Khalid M. Chaudhary, Umair Talib* \\ Institute of Agricultural Extension and Rural Development, University of Agriculture Faisalabad, Pakistan.
}

\begin{abstract}
A B S T R A C T
Pakistan is one of the largest citrus producer and leading exporter of Kinnow in world. Average production of this vital fruit comparatively lower than potential and in result, minor contributions comes to national economy and livelihoods of the growers. Present study was designed to analyze factors impeding citrus supply chain in Toba Tek Singh District of the Punjab province. Through multistage sampling technique 120 citrus growers were selected. Data were collected through face to face interview technique with the help of structured, validated, reliable and pre-tested questionnaire. Collected data were analyzed by using Statistical package for Social Sciences (SPSS). Findings unveiled that black marketing of fertilizers, shortage of labor; lack of technical knowledge and shortage of finance were major factors impeding production of citrus crop. Monopoly of middle-man; late payments by the dealers; lack of storage facilities; high storage cost and less price of citrus set by the government were leading barriers of marketing. Study recommended that development of effective marketing system, subsidies on inputs and initiation of direct marketing for small farmers in particular. Study further urges development of affordable machinery for growers to encounter labor shortage problems.
\end{abstract}

Keywords: Production, marketing, factors, citrus supply chain, Punjab.

\section{INTRODUCTION}

Citrus is one of the leading fruit crops of Pakistan being income source and source of foreign exchange earnings. Since the introduction of kinnow mandarin (Citrus reticulate Blanco.) in the country, its production has been increasing steadily to fulfill the growing demands at home and abroad. Citrus has great importance in view of its dietary and economic values. Kinnow is a valuable fruit occupies 1st position amongst all fruits both in terms of area and production. However, Pakistan has 12th position in citrus production in the world (FAO, 2005). Total area under citrus cultivation during 201011 was 194528 hectares with production of 1982191 (tons) and during 2014-15 was 192832 hectares with production of 2395550 (tons) (Government of Pakistan, 2016). About 95 per cent of the citrus area is located in Punjab. Of the total area under fruits, 29.55 per cent is under citrus and 60 per cent of it is under kinnow with more than 75 per cent production of total citrus fruits. Under citrus fruits, kinnow area, production and exports

* Corresponding Author:

Email: umair1754@gmail.com

(c) 2018 ESci Journals Publishing. All rights reserved. are at the top. More than 90 per cent of citrus exports are those of kinnow. Assuming that all kinnow produced in Punjab is domestically marketed, the employment generated from its production and marketing is estimated at about 23.48 million labour days or fulltime jobs for more than 75,000 people (about 57 million labour days in production and remaining in marketing sectors) (Sargodha online, 2016).

The fruit bearing life of citrus orchard is 20-30 years which is lower compared to other citrus producing countries of world, where its span goes up to 50 years. The basic factor affects the citrus supply chain is less use of high-quality citrus production techniques. Farmers are not realizing the orchard as an endeavour rather they grow as additional crops in the field. So, they are not able to fulfil the demand of kinnow crop at the time of need; they create a huge gap in citrus production as they do intercropping of different crops in citrus orchard which cause unfavourable losses to the citrus plants and production (Nawaz et al., 2011).

Analysis of the data show that lack of technical assistance, lack of improved varieties, lack of irrigation facilities, diseases attack and natural disaster (flood) 
were perceived to be the related problems faced by citrus growers for citrus low productivity in the study area (Iqbal \& Kamal, 2014).

Citrus supply chain across Pakistan has turned to ineffective, in results net returns are diminishing with the passage of time. Multiple factors are responsible for this ineffective supply chain including variant climatic conditions (Zekri, 2011). Inadequate technical support, poor availability of improved varieties, outdated irrigation approach, infestation of diseases and abrupt climatic changes are stressors for the supply chain (Iqbal and Kamal, 2014). Poor planning and quality ignorance are additional factors affecting supply (FAO, 2005). Poor quality assurance followed by adoption of traditional packaging practices appear inconvenient for higher returns in international market (Khan et al., 2011). This miserable condition is costing loss of millions to national economy and livelihoods of the growers.

In true sense, effective citrus supply chain can harness best outcomes and attract international market. The quality produce can boost livelihoods and present significant share in national economy (Khan et al., 2011). Apart from citrus, entire horticulture crops are highly competitive in global market and grab higher returns. Processed horticulture products have had more success in higher income markets. Citrus in this regard is special because of strong competitive edge in kinnow mandarins. But despite being world's largest exporter of kinnow mandarins, entry in developed country markets is scanty so far, possibly due to their excessive seed content and quality issues. Considering this importance of citrus fruit in national economy and livelihoods, this study was planned to probe those factors which are affecting citrus supply chain in Toba Tek Singh district of Province Punjab

Several studies emphasized the issue of citrus supply chain constraining factors in Pakistan. Johnson (2006) has estimated that citrus fruits in Pakistan are estimated at 40 percent while according to ACIAR (2008) \& Khan (2008) 35 percent of the total produce of citrus in Pakistan is lost during supplying the fruit form one to another place. After all these studies, citrus supply chain in Pakistan is affected by various factors. Therefore, this study was planned to limelight this issue that our country may able to mitigate these factors

\section{METHODOLOGY}

Among all the provinces in Pakistan, Punjab is the 2nd largest province by means of area scattering on 206,344 km2 after Baluchistan. About 95\% of the citrus area is located in Punjab. Of the total area under fruits, $29.55 \%$ is under citrus. The major citrus producing districts are Sargodha and Toba Tek Singh districts across Punjab province (Govt. of Punjab, 2016).

For this research, District Toba Tek Singh was purposively selected considering extensive production of citrus in the region. Moreover, research-based literature regarding citrus supply chain in this area was scanty. The study district comprised of 04 sub-districts (Tehsils) and considering limitations of time and resources, study was restricted to one sub-district. Through random selection, sub-district Toba Tek Singh was chosen as study area. Interestingly, Sub-district Toba Tek Singh was the largest in terms of citrus cultivation area and production among all sub-districts of study district.

All citrus growers residing in selected area served as population for the study and sample was selected through multi stage random sampling technique. On first stage, study district was selected while on second stage, study-sub-district was selected at random. There were total 32 Union Councils in study sub-district. Of the total 32, 29 were rural while 03 were urban by nature. On third stage. From 29 rural union councils, 06 were selected randomly. On fourth stage, one village from each selected Union Council was selected thereby making total 06 villages from where study sample was assumed to be chosen. From each selected village, 20 respondents who were typical citrus growers were selected thereby making total sample size of 120 citrus growers. The list of sub-districts, union councils, villages and citrus growers provided by the Directorate of Fruits and Vegetable Development Project, Toba Tek Singh served as sampling frame and facilitate researcher to opt multi stage random selection. This random selection eliminated the bias and gave equal opportunity to each respondent to be selected.

Study was entirely quantitative in nature, therefore, keeping study objectives in mind, questionnaire was prepared as research instrument. Questionnaire was structured, and validity was assessed through face validity technique while reliability was assured through Cronbach alpha. Prior final data collection, instrument was pre-tested on 20 respondents other than sample. Based on pre-testing results some minor revisions in instrument was incorporated. Final data were collected through face to face interview technique. 
Collected data were statistically analyzed using Statistical Package for Social Sciences (SPSS). Means, standard deviation, and weighted score were computed for drawing conclusions and formulating recommendations.

\section{RESULTS AND DISCUSSIONS}

Socio-economic characteristics of the Respondents: Socio-economic attributes of the respondents unveiled that about one fifth $(18.3 \%)$ respondents were of less than 35 years of age while less than half $(47.5 \%)$ respondents were of between 36-50 years and 34.2\% respondents were old aged (above 50). Majority of the respondents $(80 \%)$ were literate while one fifth $(20 \%)$ respondents were illiterate. Among literate respondents, about $16.7 \%$ were educated up to primary level while $18.3 \%$ were educated more than matriculation. Vast majority of respondents (70\%) were owner of their land while remaining respondents were tenants or owner cum tenants. Likewise, majority of the respondents (76\%) were small farmers having less than 12 . Acres of land while more than half (54\%) respondents had citrus cultivation less than 12.5 acres of land. Growers were experienced in citrus cultivation as average year of experience was approximately 16.5 years. Regarding cultivation of varieties, Kinnow was the prominent variety under practices among respondents.

Table 1. Production constraints as perceived by the citrus growers.

\begin{tabular}{lccc}
\hline Production Constraints & Weighted score & Mean & Rank \\
\hline Black marketing of fertilizer & 541 & $4.66 \pm 0.474$ & 1 \\
Small land holding & 540 & $4.50 \pm 0.810$ & 2 \\
Shortage of labour & 521 & $4.34 \pm 0542$ & 3 \\
Costly mechanization & 507 & $4.22 \pm 0.783$ & 4 \\
Monopoly of dealers & 500 & $4.17 \pm 0.374$ & 5 \\
Less accessibility of fertilizer & 480 & $4.00 \pm 0.580$ & 6 \\
Lack of technical knowledge & 477 & $3.98 \pm 0.679$ & 7 \\
Shortage of finance & 462 & $3.85 \pm 0.513$ & 8 \\
Adulteration in chemicals & 324 & $3.34 \pm 0.978$ & 9 \\
High prices of inputs & 353 & $2.94 \pm 0.833$ & 10 \\
Poor awareness of recommended production practices & 279 & $2.79 \pm 0.608$ & 11 \\
Inadequate contact with experts & 150 & $2.68 \pm 1.266$ & 12 \\
Poor availability of diseases free plants/nursery & 224 & $2.60 \pm 1.817$ & 13 \\
Accessibility of disease free material & 211 & $2.27 \pm 1.490$ & 14 \\
Facility of imported certified material for citrus & 186 & $2.11 \pm 1.272$ & 15
\end{tabular}

Production constraints being faced by the citrus growers: Data presented in Table 1 revealed that black marketing of fertilizers appeared prominent obstacle with highest mean value of $4.66 \pm 0.474$. Small land holdings appeared second leading constraints with mean value of $4.50 \pm 0.810$ followed by shortage of labour holding 3rd ranking with mean value of $4.34 \pm 0542$. During informal discussion respondents elaborated that they are facing labour shortage which not only delays the farm operations but also affects the quality of produce as available labour is not skilled. Majority of small farmers not only in study area but also across Pakistan are small farmers and these losses pertaining to labour shortage meant them a lot. Their feeble financial position doesn't allow them to adopt mechanized farming to encounter problem of labour shortage.
Mechanized farming is not only inaccessible to small farmers but also an expensive option. Extensive mechanization was further reported as 4th leading barrier with mean value of $4.22 \pm 0.783$. Ghafoor et al. (2008) had reported that inadequate finance and higher prices of inputs were major challenges for citrus producers in Pakistan. Finance shortage and expensive inputs essential for sustained production lowered the potential of citrus production in district Sargodha (Ashraf et al., 2014). In the same district, Ashraf et al. (2015) unveiled that growers were practicing manual application of spray and other operations because of expensive technologies, particularly mechanization tools. In converse to these findings, findings a labour has turned to major dilemma. According to Hassan \& Ahmed (2015) labour shortage is the prominent constraint of 
present time faced by citrus growers. A decade ago, similar kind of findings were reported by Johnson (2006). It may be summarized that with the passage of time shortage of labour is rising and need of affordable machinery is rising. Among various other constraints, Adulteration in chemicals, high prices of inputs.
Inadequate awareness regarding production practices, inadequate contact with experts, sluggish availability of disease free plants, and facility of imported and certified material were some least influential constraints. The impact of these constraints was limited under medium level.

Table 2. Ranking of problems regarding marketing.

\begin{tabular}{lccc}
\hline Marketing Constraints & Weighted score & Mean & Rank \\
\hline Monopoly of middle man & 549 & $4.65 \pm 0.478$ & 1 \\
Inadequate Storage facilities & 462 & $4.53 \pm 0.841$ & 2 \\
Late payment by the dealers & 510 & $4.25 \pm 0.538$ & 3 \\
Shortage of transport facilities & 506 & $4.22 \pm 0.553$ & 4 \\
High storage cost & 476 & $3.97 \pm 1.076$ & 5 \\
Information about market prices & 418 & $3.87 \pm 0.833$ & 6 \\
High carriage and other handling charges & 457 & $3.81 \pm 0.946$ & 7 \\
Distant markets & 415 & $3.52 \pm 0.535$ & 8 \\
Less price of citrus in markets & 416 & $3.47 \pm 0.697$ & 9 \\
High market committee fee & 398 & $3.43 \pm 0.749$ & 10
\end{tabular}

Marketing constraints being faced by the citrus growers: Data depicted in Table 2 summarized different constraints as perceived by the growers, affecting marketing of citrus. Monopoly of middleman appeared leading constraint with mean value of $4.65 \pm 0.478$, making marketing uncertain. Inadequate storage facilities for enhanced shelf life of citrus fruits stood on 2 nd rank with mean value of $4.53 \pm 0.841$. late payments offered by the dealers once the produce is sold by producer was another constrain getting 3rd rank with mean value of $4.25 \pm 0.538$. shortage and inappropriate transportation facilities has been prime source of quality reduction and fruit loss. Hence, stood on 4th rank with mean value of $4.22 \pm 0.553$. Iqbal \& Khan (2014) augmented poor marketing facilities for citrus growers and extensive cost of transportation faced by the growers. Different literature indicated that marketing system in Pakistan is traditional resulting in poor efficiencies (Sharif et al., 2005). There are generally great differences between prices paid by consumer and those received by producers (Toaha, 1974); Qureshi (1974); Sattar, et al. (1976); Siddiqui (1979); Memon (1978); Khan (1980); \& Mohy-ud-din (1991)]. On the other hand, very little research has been done on domestic marketing of fruits. Improvements of roads, bridge construction and spot maintenance make it easy for farmers to reach at local markets.

There is a need to make better policies to create integrity of remote areas with urban areas through provision and improvement of road networks (Torbjorn \& Bharat, 2012). Better transport system should be provided to farmers which reduce transport costs and travel time results in better marketing and increased production (IFAD, 2001).

\section{CONCLUSION AND RECOMMENDATIONS}

Citrus supply chain in study area appeared partially effective because of militating factors persisting from the many years. Scanty supply chain offered low price of produce to growers. Traditional mechanism of farming, high cost of inputs, expensive mechanization and labour shortage were the prominent factors obstacle supply chain. While, defective marketing, influence of intermediaries in marketing system were additional barriers in way of citrus marketing. Study urge development of sound marketing system for citrus growers, subsidies on inputs and initiating direct marketing for small farmers in particular. Study further urges development of affordable machinery for growers to encounter labor shortage problems.

\section{REFERENCES}

Ashraf, S., Khan, G. A., Ali, S., Iftikhar, M., Luqman, M., \& Hassan, M. Z. Y. (2015). Patterns and limitations of micronutrients application for citrus production in Sargodha: a challenge for extension education in the Punjab. Journal of Agricultural Research (03681157), 53(1). 
Ashraf, S., Khan, G. A., Ali, S., Iftikhar, M., \& Mehmood, N. (2014). Managing insect pests \& diseases of citrus: on farm analysis from Pakistan. Pakistan Journal of Phytopathology, 26(2), 301-307.

Food and Agricultural Organization (FAO). (2005). FAO Production Year Book, FAO, Rome, Itlay.

Ghafoor, U., Muhammad, S., \& Chaudhary, K. M. (2008). Constrains in availability of inputs and information to citrus (kinnow) growers of tehsil Toba Tek Singh. Pakistan Journal of Agricultural Sciences, 45(4), 520-522.

Government of Pakistan. (2016). Ministry of National Food Security \& Research Islamabad.

Government of Punjab. (2016). Punjab Development Statistics. Bureau of Statistics. Government of the Punjab, Lahore, Pakistan.

Horticultural Crops Development Authority [HCDA]. (2009). Strategic Plan 2009-2013. Nairobi: HCDA.

International Fund for Agricultural Development [IFAD]. (2001). Rural poverty report. Rome: International Fund for Agricultural Development.

Iqbal, S., and T. Kamal. 2014. Factors Affecting Citrus Productivity in District Dir Lower, Journal of Economics and Sustainable Development ,5(27),197-200

Johnson, G. (2006). Pakistan citrus industry challenges: Opportunities for Australia-Pakistan collaboration in research, development and extension. In Pakistan: Citrus Industry Survey and Workshops.

Khan, Abid M. Sami (1980) Marketing Infrastructure, Margins and Seasonal Price Variation of Selected Agricultural Commodities in Sindh Province of Pakistan. Tandojam: Department of Agricultural Economics and Rural Sociology, Sindh Agriculture University.

Khan, M.B., Chaudhry, I. S. \& Akhtar, M. H. (2011). Cost benefit analysis of cotton production and processing by stakeholders: The case study of Multan and Bahawalpur region. American Journal of Scientific Research. 13: 131-141.

Khan, S.R.A. (2008). Citrus quality to meet global demand. Pakissan.com. http://www.pakissan.com/english/agri.overview /citrus.quality.to.meet.global.demand.

Memon, R. A. (1978) Marketing Infrastructure, Margins and Seasonal Price Variation of Selected Agricultural Commodities in Sindh Province of
Pakistan.

Mohy-ud-din, Q. (1991) Improving Marketing System of Citrus Fruit in Punjab Province. Pakistan Agricultural Development Review 1:2, 35-44.

Nawaz, A., Afzal M. \& Ahmed, W. (2011). Obstacles In Development Of Citrus Industry Of Pakistan And Their Possible Solutions. Available at http://agrihunt.com/horti-industry/995obstacles-in-development-of-citrus-industry-ofpakistan-and-their-possible-solutions.html.

Ogunlade, I. (2007). Backyard fish farmers information needs in Osun state, Nigeria. Available at: http://www.aaaeafrica.org/proceedings2/002/Ogunlade.pdf

Qureshi, S. K. (1974) The Performance of Village Markets for Agricultural Produce: A Case Study of Pakistan. The Pakistan Development Review 13(3), 280307.

Sargodha News [SN]. (2016). Sargodha Citrus. Sunday 25 Sep 2016. Retrieved from http://sargodhanews.com/bsunday. on October 216, 2016

Sattar, et al. (1976) Marketing of Agricultural Products in Pakistan. Lahore: Punjab Board of Economic Enquiry, Pakistan.

Sharif, M., Farooq, U., Malik, W., \& Bashir, M. (2005). Citrus Marketing in Punjab: Constraints and Potential for Improvement [with Comments]. The Pakistan Development Review, 673-694.

Siddiqui, S. A. (1979) Marketing of Agricultural Products in Sindh. Tandojam: Department of Agricultural Economics and Rural Sociology, Sindh Agricultural University, Pakistan

Tahir, A. (2004). Marketing of citrus fruit in Pakistan. Thesis, Deptt. of Commerce, Univ. of Karachi.

Toaha, M. (1974) Estimation of Marketing Margins and Measurement of Seasonal Variation of Selected Agricultural Commodities in Sindh Province of Pakistan. Tandojam: Sindh Agricultural College, Pakistan.

Torbjorn A. \& Bharat. P.B. (2012). Contribution of rural roads to access to and participation in markets: Theory and Results from Northern Ethiopia. J. Transportation Technol. 2,165-174.

Zekri, M. (2011). Factors affecting citrus production and quality. Trees. 